\title{
Pentachlorophenol affected both reproductive and interrenal systems: In silico and in vivo evidence
}

\author{
Lihua Yang a , Jinmiao Zha b, c, *, Zijian Wang ${ }^{\mathrm{d}}$ \\ a State Key Laboratory of Freshwater Ecology and Biotechnology, Institute of Hydrobiology, Chinese Academy of Sciences, Wuhan 430072, China \\ b State Key Laboratory of Drinking Water Science and Technology, Research Center for Eco-Environmental Sciences, Chinese Academy of Sciences, Beijing \\ 100085, China \\ c Beijing Key Laboratory of Industrial Wastewater Treatment and Reuse, Research Center for Eco-Environmental Sciences, Chinese Academy of Sciences, \\ Beijing 100085, China \\ d State Key Laboratory of Environmental Aquatic Chemistry, Research Center for Eco-Environmental Sciences, Chinese Academy of Sciences, P.O. Box 2871, \\ Beijing 100085, China
}

\section{H I G H L I G H T S}

- The effects of PCP on steroid system were studied by in silico and in vivo assays.

- In silico results indicated interacting potency with steroid receptors by PCP.

- PCP caused adverse effects on reproductive and interrenal system in rare minnow.

- The HPG/I axis of rare minnow showed different response at 14 th and 28th day.

\section{A R T I C L E I N F O}

\section{Article history:}

Received 28 July 2016

Received in revised form

20 September 2016

Accepted 21 September 2016

Available online 30 September 2016

Handling Editor: David Volz

\section{Keywords:}

Pentachlorophenol

Molecular docking

Chinese rare minnow (Gobiocypris rarus)

Reproductive system

Interrenal system
G R A P H I C A L A B S T R A C T

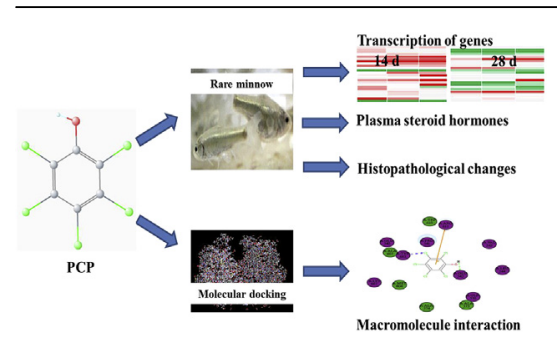

\begin{abstract}
A B S T R A C T
The present study investigated the effects on reproductive and interrenal system by pentachlorophenol (PCP) using in silico and in vivo assays. Molecular docking results indicated interacting potency of PCP with steroid receptors (ER $\alpha, \mathrm{ER} \beta, \mathrm{AR}, \mathrm{GR}$ ) but not Cytochrome P450 enzymes (CYPs). In the in vivo assay, sexually matured rare minnow (Gobiocypris rarus) was exposed to environmental relevant concentrations of PCP $\left(0,0.5,5,50 \mu \mathrm{g} \mathrm{L}{ }^{-1}\right)$. In male fish, 14-d exposure caused up-regulation of mRNA levels of hepatic er $\alpha, \operatorname{er} \beta, a r, g r, v t g$ and gonadal er $\alpha, v t g, a r, d m r t 1$, providing evidence for agonistic activities for steroid receptors by PCP. The up-regulated mRNA of gnrh, crf, pomc in the brain also indicated feedforward responses of the hypothalamic-pituitary-gonadal/interrenal (HPG/I) axis. However, at 28th $\mathrm{d}$ the feed-forward response of the HPG axis seemed eased back and the HPI axis showed negative feedback responses. Corresponding changes including increases of plasma steroid hormones, inhibition of spermatogenesis, and decreased RSI were observed in male fish upon 28-d exposure to PCP. In the females, a transition from feed-forward responses to negative feedbacks of the HPG/I axis was also indicated by the transcriptional profiles at 14th and 28th day. Corresponding changes including increased E2, T and decreased C levels, degenerated ovaries, and decreased GSI and RSI were also observed. Overall, we concluded that PCP could interfere with steroid receptors, evoke responses of HPG/I axis, and finally
\end{abstract}

\footnotetext{
* Corresponding author. State Key Laboratory of Drinking Water Science and Technology, Research Center for Eco-Environmental Sciences, Chinese Academy of Sciences, P.O. Box 2871, Shuangqing Rd 18, Haidian District, Beijing 100085, China.

E-mail addresses: jmzha@rcees.ac.cn, jinmiaozha@gmail.com (J. Zha).
} 
result in adverse effects on reproductive and interrenal system in rare minnow at environmental relevant concentrations.

\begin{tabular}{|c|c|c|c|}
\hline \multirow{2}{*}{\multicolumn{2}{|c|}{ Abbreviations }} & VTG & Vitellogenin \\
\hline & & DMRT1 & Doublesex and Mab-3 Related Transcription Factor 1 \\
\hline \multirow{2}{*}{\multicolumn{2}{|c|}{$\begin{array}{l}\text { HPG/I axis Hypothalamic-Pituitary-Gonadal/Interrenal (HPG/I) } \\
\text { Axis }\end{array}$}} & HSPs & Heat Shock Proteins \\
\hline & & CYP & Cytochrome P450 \\
\hline GnRH & Gonadotropin-Releasing Hormones & GSI & Gonadosomatic Index \\
\hline CRF & Corticotropin-Releasing Factor & RSI & Renalsomatic Index \\
\hline POMC I & Proopiomelanocortin & SG & Spermatogonia \\
\hline $\mathrm{T}$ & Testosterone & SC & Spermatocytes \\
\hline E2 & Estradiol & $\mathrm{SZ}$ & Spermatozoa \\
\hline $\mathrm{C}$ & Cortisol & PV & Previtellogenic Oocytes \\
\hline ER & Estrogen Receptor & EV & Early Vitellogenic Oocytes \\
\hline AR & Androgen Receptor & $\mathrm{V}$ & Vitellogenic Oocytes \\
\hline GR & Glucocorticoid Receptor & A & Atresia \\
\hline
\end{tabular}

\section{Introduction}

Pentachlorophenol (PCP) were extensively used for decades in agriculture and industry (Ge et al., 2007; Zheng et al., 2011, 2012). Comprehensive monitor revealed ubqintious distribution of PCP in Chinese surface water (Gao et al., 2008; Han et al., 2009), and the reported concentrations was up to $103.7 \mu \mathrm{g} \mathrm{L}^{-1}$ in water and $630 \mu \mathrm{g} \mathrm{kg}^{-1}$ lipid in the bile of fish from Dongting Lake (Zheng et al., 2000). The pollution of PCP may pose a threat to the wellbeing of aquatic species, and it is crucial to analyzing its ecological risk. However, the use of toxicity information for nonnative species is not recommended to represent a local problem (Davies et al., 1994). Studies from Jin et al. (2012a) also revealed slightly higher sensitivity by Chinese endemic species than non-native species when exposed to PCP. For these reasons, there is an increasing demand for chronic toxicity data especially for local species in site-specific risk assessment.

The reported adverse effects of PCP include immunotoxicity, carcinogenicity, oxidative stress and metabolic disorders (Yin et al., 2006; Fang et al., 2010; Pietsch et al., 2014; Chen et al., 2015). PCP has been demonstrated to display estrogenic, anti-estrogenic, antiandrogenic, thyroid receptor and retinoid $\mathrm{X}$ receptor antagonistic activity in vitro (Suzuki et al., 2001; Jung et al., 2004; Orton et al., 2009; Li et al., 2008a, 2008b, 2010b) and disturb the hypothalamic-pituitary-gonadal (HPG) axis in vivo (Zha et al., 2006: Zhang et al., 2008a). However, the underlying mechanism such as molecular initiating event (MIE) and the following regulating process has not been fully understood. It has also been noted that the genes and proteins in HPG axis often showed inconsistent responsive profiles with the change of time and concentration when exposed to exogenous (Andreassen et al., 2005; Park et al., 2009; Zha et al., 2006; Liu et al., 2009), and this may result in troubles when these data were used in risk assessment. Therefore, it would be necessary to make clear the time- and dose-dependent changing profiles. Considering the close relationship between sex steroids and corticosteroids, we suppose possible influences of PCP on hypothalamic-pituitary-interrenal (HPI) axis. However, there is often a lack of these data, especially for Chinese native species.

Rare minnow (Gobiocypris rarus), which is mainly distributed in upstream of the Yangtze River, has been selected as an appropriate native species for risk assessment by Chinese government due to its small size, ease of culture and sensitivity to chemical exposure (Zha et al., 2007, 2008; Zhang et al., 2008b). In vivo models for evaluating the disruptions on HPG/I axis was developed using Chinese rare minnow, and have been validated useful for studying endocrinedisrupting effects and the underlying molecular mechanisms (Zhang et al., 2008a; Yang et al., 2010, 2011). In silico approaches such as molecular docking could provide clear view of the interactions between xenobiotic chemicals and biomolecules, thus represent potent tools for endocrine disrupting assessment ( $\mathrm{Li}$ et al., 2010a, 2012). Therefore, the main objectives of the present study were to evaluate the disrupting potency of PCP on both reproductive and interrenal systems through in silico and in vivo assays, to identify the mechanisms underlying any observations, and to provide toxicological data of native species for site-specific risk assessment in China.

\section{Materials and methods}

\subsection{Chemicals}

PCP (purity > 99.5\%) and high-performance liquid chromatography-grade dimethylsulfoxide (DMSO) were purchased from Sigma Chemical Co. (St. Louis, MO, USA).

\subsection{Test fish and culture conditions}

The rare minnow has been maintained in our laboratory for more than 13 years. The brood stock was kept in a flow-through system filled with dechlorinated tap water ( $\mathrm{pH}$ 7.2-7.6; hardness 44.0-61.0 $\mathrm{mg} \mathrm{CaCO} 3 \cdot \mathrm{L}^{-1}$ ) and subjected to a $16: 8 \mathrm{~h}$ light:dark cycle at $25 \pm 1{ }^{\circ} \mathrm{C}$. The brood stock was fed newly hatched brine shrimp (Artemia nauplii) twice a day and granule food (TetraMin, Tetra Werke, Melle, Germany) once a day. Wastes and residues were removed daily, and the test equipment and chambers were cleaned once a week. The study was approved by the institutional animal care and use committee of the Research Center for EcoEnvironmental Sciences at the Chinese Academy of Sciences (Permit Number: 153652). 


\subsection{Experimental design}

The sexually matured fish ( 10 months old $)$ used in this experiment were the offspring from one male-female pair of the brood stock. The offspring $(n=200)$ were randomly divided into ten groups of 20 fish (sex ratio 1:1). After acclimating for 2 weeks in a flow-through system, the fish were exposed to PCP at nominal concentration gradients of $0.5 \mu \mathrm{g} \mathrm{L}^{-1}, 5 \mu \mathrm{g} \mathrm{L} \mathrm{L}^{-1}$ and $50 \mu \mathrm{g} \mathrm{L}^{-1}$, respectively. The solvent control aquaria received a combination of DMSO and water $(1: 100,000, \mathrm{vol} / \mathrm{vol})$, and the water control aquaria received dechlorinated tap water only. All control and treated groups were in duplicate. The stock solutions of PCP were prepared daily in distilled water with DMSO as the co-solvent, and were pumped into the aquarium water via polytetrafluorethylene and isoversinic tubes (Abimed, Langenfeld, Germany) to obtain the appropriate PCP concentrations with the final concentrations of DMSO similar to that of the solvent control.

After 14-d exposure, four females and four males were collected from each tank. After fish were anesthetized with 0.01\% MS-222, brain, liver, gonad and kidney were carefully isolated and weighed. The samples were flash frozen in liquid nitrogen and then stored at $-80^{\circ} \mathrm{C}$ for real-time polymerase chain reaction (RT-PCR) analysis. The rest fish were sacrificed after 28-d exposure. For each fish, body length and weight were quickly determined, and the blood was collected in heparinized microcapillary tubes. The blood samples were immediately centrifuged $\left(8000 \mathrm{~g}, 10 \mathrm{~min}, 4^{\circ} \mathrm{C}\right)$, and plasma was collected and kept frozen at $-80{ }^{\circ} \mathrm{C}$ until use. The abdomen of each fish was dissected, then liver, gonad, kidney and brain were carefully isolated and weighed. Four liver (or gonad, kidney, brain) of female or male fish from each tank were collected as one replicate for RT-PCR analysis, and there were two experimental replicates for each sample. The samples were flash frozen in liquid nitrogen and then stored at $-80{ }^{\circ} \mathrm{C}$ until analysis. Gonad (or kidney) from four males and four females in each group ( 2 males and 2 females from each tank) were fixed in Bouin's solution (71\% saturated picric acid, $24 \%$ formaldehyde, $5 \%$ glacial acetic acid; Sigma-Aldrich, USA) for histopathological examination.

\subsection{Measured concentration of PCP}

The concentrations of PCP in the flow-through chambers were measured once a week during the exposure period, following method of Zhong et al. (2011) with minor modifications. Briefly, water samples $(500 \mathrm{~mL})$ from the PCP treatments were filtered by $0.45 \mu \mathrm{m}$ glass fiber filters (Millipore Corp., Bedford, MA, USA) and then enriched by solid-phase extraction cartridges. After eluted from the cartridges, the extracts were concentrated and finally analyzed using an Agilent 6890 gas chromatograph ([GC], Agilent, Santa Clara, CA, USA) equipped with an Agilent MSD 5975 mass spectrometer. The average recovery of PCP was 90\% and the detection limit of PCP was $3.6 \mathrm{ng} \mathrm{L}^{-1}$. The analyzed concentrations (mean \pm standard deviation, and \% of nominal concentration) of PCP in the test solutions during the exposure period were $0.44 \pm 0.02 \mu \mathrm{g} \mathrm{L}^{-1}$ (88\%), $4.7 \pm 0.84 \mu \mathrm{g} \mathrm{L}^{-1}$ (94\%), and $52.4 \pm 8.9 \mu \mathrm{g} \mathrm{L}^{-1}(105 \%)$, for the $0.5,5,50 \mu \mathrm{g} \mathrm{L}^{-1}$ treatments, respectively. The deviations of measured concentrations of PCP from the nominal concentrations were less than $15 \%$, so nominal concentrations were used in the following text.

\subsection{Tissue somatic index}

The tissue somatic indices were calculated as:

$$
\begin{gathered}
\text { Gonadosomatic index }(\mathrm{GSI})=\text { gonad weight }(\mathrm{g}) / \text { body } \\
\text { weight }(\mathrm{g}) \times 100 ;
\end{gathered}
$$

Hepatosomatic index (HSI) = liver weights $(\mathrm{g}) /$ body

$$
\text { weights }(g) \times 100 \text {; }
$$

Renalsomatic index $(\mathrm{RSI})=$ kidney weight $(\mathrm{g}) /$ body

$$
\text { weight }(\mathrm{g}) \times 100 \text {. }
$$

\subsection{Histopathology}

After $24 \mathrm{~h}$ gonad (or kidney) samples fixed in Bouin's solution were transferred to $70 \%$ ethanol and processed routinely according to standard histological methods and embedded in paraffin wax as described by Wolf et al. (2004). The gonad (or kidney) from each fish were horizontally cut to sections at 3-4 $\mu \mathrm{m}$ and stained with hematoxylin and eosin, and the section of the paraffin blocks were analyzed on a Axioskop 2 mot plus optical microscope (Zeiss, Germany) and digitized with a AxioCam digital camera (Zeiss) using the Application Suite software AxioVision Rel. 4.5 (Zeiss).

For testis sections, two digital images using the $10 \times$ microscope objective and two using the $40 \times$ microscope objective were obtained (i.e., 4 images per fish and 16 images total per treatment). Different cell types including spermatogonia (SG), spermatocytes (SC), spermatozoa (SZ) were manually tagged within each digital images. For ovarian sections, four digital images using the $10 \times$ microscope objective were obtained (i.e., 4 images per fish and 16 images total per treatment). Ovarian follicles were manually tagged with different cell types including previtellogenic oocytes (PV), early vitellogenic oocytes (EV), vitellogenic oocytes (V), and atresia (A) within each digital images. Tagging was performed by a single pathologist to avoid inconsistencies. Percentages of each cell types were calculated in male and female fish, respectively.

\subsection{Plasma steroid hormones}

Plasma steroid hormones (17b-estradiol [E2], testosterone [T] and cortisol $[\mathrm{C}]$ ) were measured using the enzyme-linked immunosorbent assay (ELISA) kits (Shanghai Hufeng Chemical Industry Co., China) according to the manufacturer's instructions. The observation that the dilution curves of immunoreactive steroid hormones of rare minnow plasma were parallel to the standard curves validated the use of RIA for measuring steroid hormones in rare minnow plasma. The assay sensitivity for C, E2 and T were $2 \mathrm{ng} \mathrm{mL}-1.5 \mathrm{pg} \mathrm{mL}^{-1}$ and $6 \mathrm{pg} \mathrm{mL}^{-1}$, respectively, and the intraassay coefficients of variation were all $<10 \%$. All samples were analyzed simultaneously to avoid interassay variability.

\subsection{Relative quantification by real-time $P C R$}

Relative expression of brain gonadotropin-releasing hormones (gnrh) and Cytochrome P450 19B (cyp19b), corticotropin-releasing factor (crf), proopiomelanocortin (pomc), hepatic estrogen receptors (er $\alpha$ and $e r \beta$ ), vitellogenin ( $v t g)$, androgen receptor (ar), glucocorticoid receptor ( $g r$ ) and Cytochrome P450s (cyp11a, cyp17a and cyp19a), gonadal er $\alpha, e r \beta, v t g$, ar, Doublesex and mab-3 related transcription factor 1 (dmrt1) and heat shock proteins (hsp70, hsp90), renal crf, pomc, gr, hsp70, hsp90 were determined in male and female rare minnow after exposure to PCP for 14 and $28 \mathrm{~d}$, respectively. Extraction, purification, and quantification of total RNA, first-strand CDNA synthesis, and real-time PCR were 
performed as described previously (Yang et al., 2010) in Mx3005P RT-PCR system (Stratagene, USA) using Brilliant II SYBR Green QPCR master kits (Stratagene, USA). The cycling conditions used were: an initial denaturation step of $95^{\circ} \mathrm{C}$ for $10 \mathrm{~min}$, followed by 40 cycles of $95^{\circ} \mathrm{C}$ for $30 \mathrm{~s}, 57^{\circ} \mathrm{C}$ for $40 \mathrm{~s}$ and $72^{\circ} \mathrm{C}$ for $30 \mathrm{~s}$, and the last cycle of $95^{\circ} \mathrm{C}$ for $30 \mathrm{~s}, 57^{\circ} \mathrm{C}$ for $30 \mathrm{~s}$ and $72^{\circ} \mathrm{C}$ for $60 \mathrm{~s}$ for dissociation curve. All of the cDNA samples were analyzed in triplicates (technical replicates). The control, which contained all of the reaction components except for the template, was included in all experiments. Prior to the transcriptional assay, we assessed the transcriptional stability of commonly used reference genes such as rpl8, 18s, gapdh, $\beta$-actin using geNorm analyses (http://medgen.ugent.be/genorm). The results indicated $\beta$-actin as the most stable gene under present experimental conditions and was chosen as an internal control. The mRNA expression was normalized for $\beta$-actin mRNA expression. The primer pairs used for real-time PCR were listed in Table S1.

\subsection{Molecular docking}

Molecular docking was performed and binding energies were calculated for all docked compounds using Discovery Studio 4.0 (Accelrys Software, San Diego, CA, USA). The three-dimensional (3D) structures of chlordecone were obtained from the PubChem Substance database (http://www.ncbi.nlm.nih.gov/pcsubstance) and optimized with the MMFF94 method. The crystal structure of ER $\alpha$ (agonistic-1ERE; antagonistic-3ERT), ER $\beta$ (agonistic-2JJ3; antagonistic-1L2J), AR (agonistic-2AM9; antagonistic-1Z95), GR (agonistic-4P6X; antagonistic-3H52), CYP11A1 (agonistic- 3N9Y; antagonistic-3N9Z), CYP17A1 (agonistic-3RUK; antagonistic3SWZ), CYP19A1 (agonistic-3S79; antagonistic-4GL5) were obtained from the RCSB protein data bank (http://www.pdb.org), and used for docking modeling after preparation. After active sites were defined, docking poses were generated using the Libdock module. During the simulation, docking preferences was set as high quality and conformation method was set as best. The steepest descent method was used for minimization. Other parameters were set as default values. The binding energies were obtained by calculate binding energies tools with default parameters. The conformation with the highest libdock score for each protein was selected as the most likely bioactive conformation.

\subsection{Statistical analysis}

All quantitative data are expressed as means \pm standard error (SEM). Prior to one-way analysis of variance (ANOVA), data normality and homogeneity of variance were analyzed using the Kolmogorov-Smirnov and Levene's tests, respectively. If necessary, data were log-transformed to achieve approximate normality. Dunnett's test were used to compare data between treatments using SPSS (version 17.0). A probability of $p<0.05$ was considered to be statistically significant.

\section{Results}

\subsection{In silico simulate of interactions between PCP with key proteins}

No poses were generated for PCP with the CYPs (CYP11A1, CYP17A1 or CYP19A1) or the antagonistic conformations of ER $\alpha$ and GR. In contrast, PCP could be docked with the agonistic conformations of $E R \alpha, E R \beta, A R$ and GR, and antagonistic conformations of ER $\beta$ and AR. The interacting modes of PCP and the agonistic conformations of the receptors are shown in Fig. 1. H-bond was found formed between the hydrogen atom with the residues of PRO325 in ER $\alpha$-PCP complex (Fig. 1A). Analyses of the GR-PCP complex (Fig. 1D) revealed $\mathrm{H}$-bond between the hydrogen atom with the residues of GLU542 and chlorine atom with TYR663, and also $\pi$ cation interactions mediated by ARG611. Besides, van der Waals force (green disc) followed by electrostatic forces (purple disc) as well as hydrophobic force indicated by the solvent accessible surface area (SASA) (light blue) may be mainly attributed to the interaction of PCP with ER $\beta$ (Fig. 1B) and AR (Fig. 1C). The binding energies of complex for PCP with these proteins were $-74.2,-63.9,-61.8$, and $-77.7 \mathrm{kcal} \mathrm{mol}^{-1}$, respectively.

\subsection{In vivo effects on $H P G / I$ axis in rare minnow}

There were no statistically significant differences in growth, tissue somatic indices, plasma steroid hormones or mRNA levels of the detected genes between the solvent control and the water control. Therefore, the water control was used as control in the following text.

\subsubsection{Body length, weight and tissue somatic indices}

The body length, body weight and tissue somatic indices were shown in Table 1. After 28-d exposure, the body length and weight were not obviously affected. - However, significant decreases of RSI were observed in the males exposed to $5 \mu \mathrm{g} \mathrm{L}^{-1}$ and $50 \mu \mathrm{g} \mathrm{L}^{-1}$ PCP and females to all concentrations $(p<0.05)$. Significantly decreased GSI were also observed in the females exposed to $0.5 \mu \mathrm{g} \mathrm{L}^{-1} \mathrm{PCP}$ $(p<0.05)$.

\subsubsection{Histopathology of gonad and kidney}

Histological inspection revealed the presence of developing oocyte including PV, EV and V in ovaries and different stages of spermatogenic cells (SZ, SC and SG) in testis from the control and treated groups (Fig. S1). The percentage of PO increased in ovaries from fish exposed to $0.5 \mu \mathrm{g} \mathrm{L}^{-1} \mathrm{PCP}$ and that of atresia increased in ovaries from fish exposed to 5 and $50 \mu \mathrm{g} \mathrm{L} \mathrm{L}^{-1} \mathrm{PCP}$ (Fig. 2A). For testis, the percentage of SG significantly increased while that of SZ decreased in fish exposed to $0.5 \mu \mathrm{g} \mathrm{L}^{-1}$ PCP. The percentage of SZ also showed decreases in testis from fish exposed to 5 and $50 \mu \mathrm{g} \mathrm{L}^{-1}$ PCP (Fig. 2B).

Microphotographs of kidney (Fig. S2) also indicated histopathological changes such as lesions in glomerulus and necrosis of the tubular epithelia in female fish exposed to $50 \mu \mathrm{g} \mathrm{L}^{-1}$ PCP.

\subsubsection{Plasma steroid hormones}

Levels of plasma steroid hormones were shown in Table 2. After treatment, levels of plasma E2 and T were significantly elevated at lower exposure concentrations $(p<0.05)$, showing inverted " $U$ " form dose-dependent relationships. Levels of plasma $C$ showed significant decrease at $0.5 \mu \mathrm{g} \mathrm{L}^{-1}$ for females but increase at $50 \mu \mathrm{g} \mathrm{L}^{-1}$ for males. The ratio of E2/T were significantly decreased in females from all PCP treatments and in males after treatment with $0.5 \mu \mathrm{g} \mathrm{L}^{-1}$ and $5 \mu \mathrm{g} \mathrm{L}^{-1} \mathrm{PCP}(p<0.05)$.

\subsubsection{Real-time $P C R$}

In the males, 14-d exposure to PCP resulted in significantly upregulated transcripts of brain gnrh, crf, pomc, cyp19b, hepatic er $\alpha$, er $\beta, v t g, a r, g r$, cyp11a, gonadal er $\alpha, v t g, a r, d m r t 1, h s p 90$ as well as interrenal $\mathrm{crf}$, pomc, $h s p 70$, and significantly down-regulated transcripts of hepatic cyp17a, cyp19a and interrenal hsp90 (Fig. 3). After 28-d exposure to PCP, the transcripts of hepatic er $\alpha, \operatorname{er} \beta, v \operatorname{tg}, g r$ gonadal vtg and interrenal $c r f$, pomc, hsp70 were up-regulated, while those of brain $c r f$, pomc, cyp19b, hepatic cyp17a, cyp19a and gonadal ar, dmrt1, hsp70, hsp90 down-regulated $(p<0.05)$. Besides, the transcriptional profiles of hetatic cyp11a showed increases at lower concentrations but decreases at higher concentrations (Fig. 3).

In the females, 14-d exposure to PCP resulted in significantly up- 


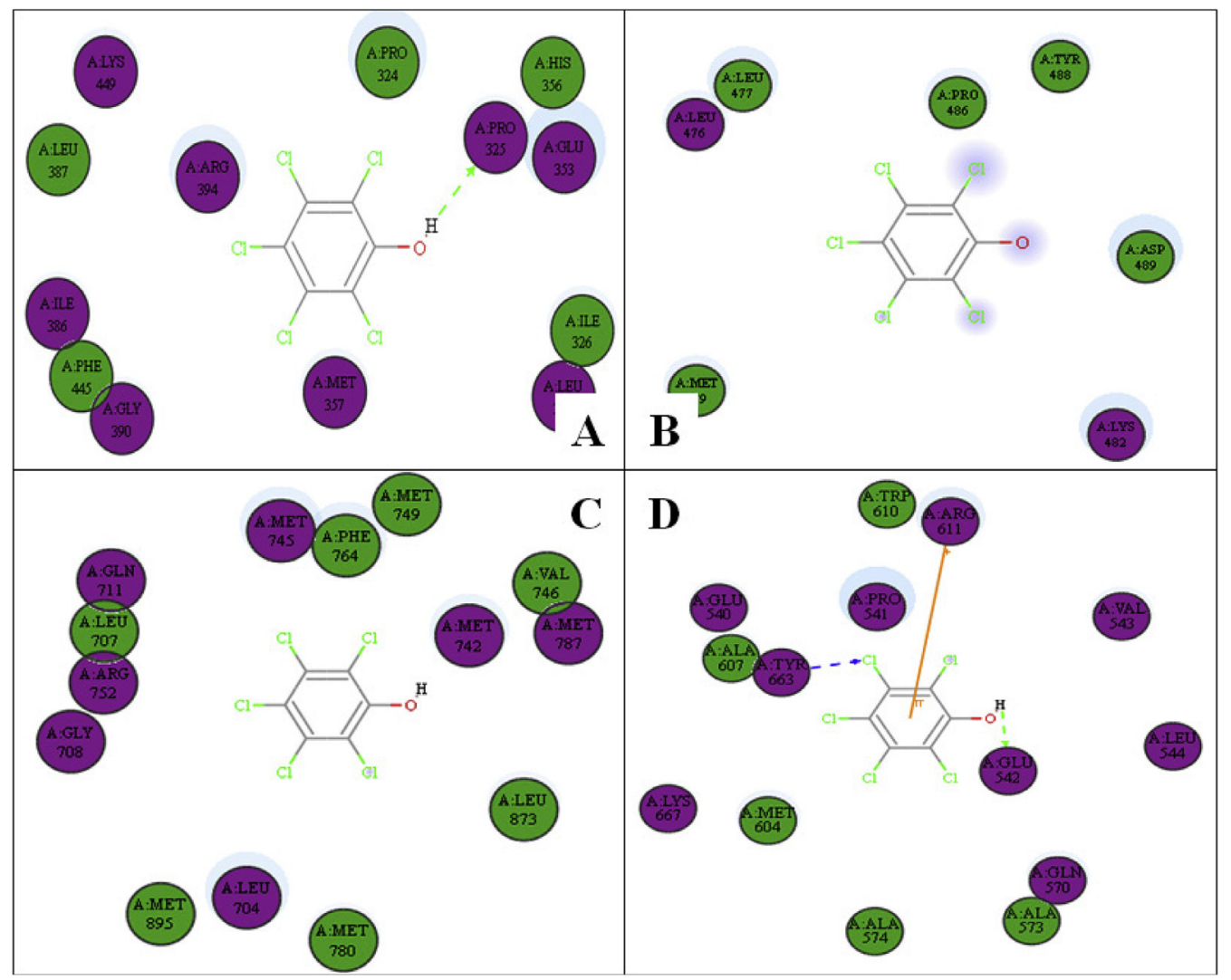

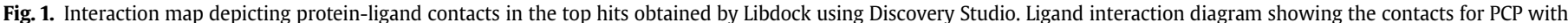

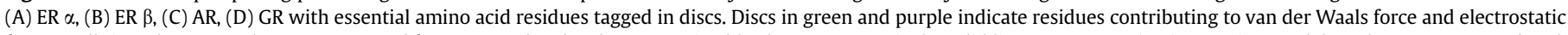

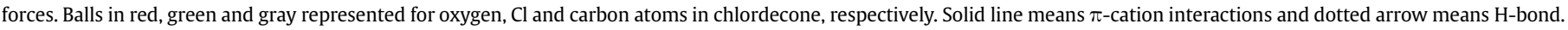
(For interpretation of the references to colour in this figure legend, the reader is referred to the web version of this article.)

Table 1

The growth and tissue somatic index of rare minnow (Gobiocypris rarus).

\begin{tabular}{|c|c|c|c|c|c|c|}
\hline \multicolumn{2}{|c|}{ Concentration $\left(\mu \mathrm{g} \cdot \mathrm{L}^{-1}\right)$} & \multirow{2}{*}{$\begin{array}{l}\text { Length }(\mathrm{mm}) \\
49.6 \pm 4.0\end{array}$} & \multirow{2}{*}{$\begin{array}{l}\text { Weight }(\mathrm{g}) \\
1.23 \pm 0.29\end{array}$} & \multirow{2}{*}{$\begin{array}{l}\text { GSI (\%) } \\
15.2 \pm 3.6^{\mathrm{a}}\end{array}$} & \multirow{2}{*}{$\begin{array}{l}\text { HSI (\%) } \\
2.39 \pm 0.48\end{array}$} & \multirow{2}{*}{$\begin{array}{l}\text { RSI (\%) } \\
0.42 \pm 0.19^{\mathrm{a}}\end{array}$} \\
\hline Female & Control & & & & & \\
\hline & 0.5 & $49.1 \pm 1.6$ & $1.28 \pm 0.40$ & $10.1 \pm 3.5^{\mathrm{b}}$ & $2.05 \pm 0.62$ & $0.27 \pm 0.08^{\mathrm{b}}$ \\
\hline & 5 & $48.5 \pm 4.1$ & $1.26 \pm 0.35$ & $13.1 \pm 4.1^{\mathrm{ab}}$ & $2.35 \pm 0.64$ & $0.24 \pm 0.11^{\mathrm{b}}$ \\
\hline & 50 & $48.0 \pm 4.3$ & $1.18 \pm 0.24$ & $13.2 \pm 3.0^{\mathrm{ab}}$ & $2.02 \pm 0.54$ & $0.22 \pm 0.14^{\mathrm{b}}$ \\
\hline \multirow[t]{4}{*}{ Male } & Control & $45.3 \pm 3.2$ & $0.79 \pm 0.12$ & $2.39 \pm 0.48$ & $1.94 \pm 0.46$ & $0.52 \pm 0.19^{a}$ \\
\hline & 0.5 & $47.5 \pm 1.1$ & $0.82 \pm 0.16$ & $2.05 \pm 0.62$ & $1.48 \pm 0.45$ & $0.38 \pm 0.16^{\mathrm{ab}}$ \\
\hline & 5 & $45.1 \pm 2.6$ & $0.79 \pm 0.15$ & $2.35 \pm 0.64$ & $1.77 \pm 0.55$ & $0.30 \pm 0.07^{\mathrm{b}}$ \\
\hline & 50 & $44.7 \pm 2.9$ & $0.84 \pm 0.23$ & $2.02 \pm 0.54$ & $2.14 \pm 0.54$ & $0.25 \pm 0.14^{\mathrm{b}}$ \\
\hline
\end{tabular}

Data are expressed as mean \pm S.E. $(n=12)$.

Within series different letters denote statistically significant differences among groups (Dunnett's test; $p<0.05$ ).

regulated transcripts of brain gnrh, hepatic er $\alpha, \operatorname{er} \beta, v \operatorname{tg}$ and $g r$ as well as interrenal $c r f$, pomc, hsp70, and significantly downregulated transcripts of hepatic ar, cyp17a, cyp19a, gonadal er $\alpha$, ar, $h s p 70, h s p 90$ as well as interrenal $h s p 90$ (Fig. 4). After 28-d exposure to PCP, the transcripts of brain gnrh, hepatic er $\alpha, \operatorname{er} \beta$, ar and $g r$ as well as interrenal crf, pomc, hsp70 were significantly up-regulated, while those of brain pomc, cyp19b, hepatic cyp17a, cyp19a, gonadal er $\alpha, \operatorname{er} \beta, d m r t 1$ as well as interrenal gr, hsp90 were down-regulated $(p<0.05)$. Besides, the transcriptional profiles of brain $c r f$, hetatic $v t g$, gonadal $h s p 70$ and $h s p 90$ showed decreases at lower concentrations but increases at higher concentrations (Fig. 4).

\section{Discussion}

To clarify the endocrine disrupting mechanism and provide useful information for site-specific risk assessment, the effects of PCP on the reproductive and interrenal system were studied. In silico results indicated interacting potency of PCP with steroid receptors but not CYPs. In the in vivo assays, exposure to environmentally relevant levels of PCP evoked disruptions on the HPG and HPI axis at transcriptional level, and resulted in changes of plasma steroid hormones (E2, T and C) levels, histopathology, and tissue somatic indices of rare minnow.

In the present study, molecular docking was used to predict the interacting potency of PCP with the agonistic and antagonistic conformations of sex steroid receptors (ER $\alpha, \mathrm{ER} \beta, \mathrm{AR}, \mathrm{GR})$ and $\mathrm{Cy}-$ tochrome P450 enzymes (CYP11A1, CYP17A1 and CYP19A1). The results showed that PCP could be docked with the agonistic conformations of ER $\alpha, E R \beta, A R, G R$, and antagonistic conformations of ER $\beta$ and AR. In addition, the binding energies of complex for PCP 

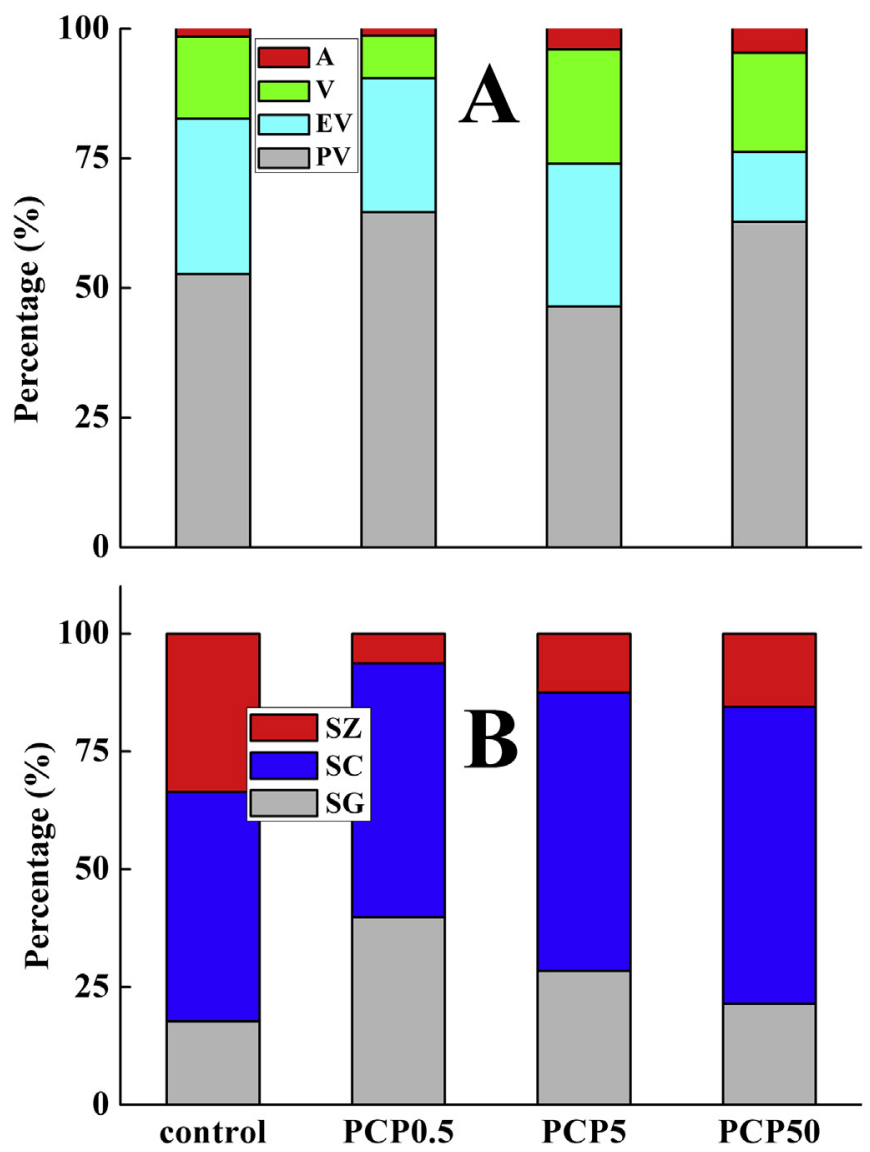

Fig. 2. Histological examination of gonad development in rare minnow (Gobiocypris rarus) after exposure to $\mathrm{PCP}$. (A) The percentages of previtellogenic (PV), early vitellogenic (EV), vitellogenic (V) and atretic (A) oocytes in ovary of female fish. (B): The percentages of spermatogonia (SG), spermatocytes (SC) and spermatozoa (SZ) in testes of male fish. Values represent the mean of 8 individual fish from 2 replicates.

with these steroid receptors were approximate equivalent. These results may provide molecular evidences for previously reported estrogenic, anti-estrogenic, anti-androgenic activity of PCP in vitro (Suzuki et al., 2001; Jung et al., 2004; Orton et al., 2009; Li et al., 2008a, 2008b, 2010b) and in vivo (Zha et al., 2006; Zhang et al., 2008a). Moreover, molecular docking results showed that PCP could not interact with any of the agonistic or antagonistic conformations of CYPs. The in vitro results from the Pubchem database (NIH, 2016) also indicated limit disrupting potency of PCP with CYP19A1. Therefore it seems reasonable to presume that the interactions with the steroid receptors might act as MIEs of PCP, evoking perturbations of the HPG/I axis and finally endocrine disrupting outcomes. In this regard, the in vivo effects of PCP on the
HPG/I axis were studied using Chinese rare minnow, and the differential responses were separately discussed in males versus females to unravel the perturbations driving the observed effects.

In the males, hepatic ers, ar, gr and gonadal er $\alpha$, ar were promoted upon 14-d exposure to PCP, providing evidence for agonistic activities for steroid receptors of PCP as indicated by our in silico observations. The gene $v t g$ has been proved to be induced by natural estrogens (i.e. E2) as well as xenoestrogens (i.e. bisphenol A, BPA) via ERs signaling (Kurosawa et al., 2002; Bjornstrom and Sjoberg, 2005). Although VTG is considered primarily synthesized in the liver, studies have shown that vtg mRNA could also be detected in extrahepatic tissues, especially the gonad, and could be induced following exposure to estrogenic chemicals (Wang et al., 2005). Dmrt1 plays critical role in male gonadal differentiation and maintenance (Ohtani et al., 2003; Matson et al., 2010) and it appears to be down-regulated in response to estrogen (Marchand et al., 2000) and up-regulated in response to androgen (Shibata et al., 2002). In the present study, vtg mRNA levels in liver and gonad and dmrt1 mRNA levels in gonad were also up-regulated in male fish upon 14-d exposure to PCP. These results provided further evidence for the agonistic activities for steroid receptors of PCP. In fish, steroid synthesis is mainly controlled by hypothalamic $\mathrm{GnRH}$ via pituitary-derived gonadotropic hormones (GtHs) and in turn the CYP enzymes (Nagahama et al., 1994; Yaron et al., 2003). Although the in silico results indicated no affinity of PCP with CYPs, we observed significantly up-regulated cyp11a mRNA and downregulated cyp17a, cyp19a mRNA in the liver of male rare minnow. These changes may attribute endocrine perturbations evoked by the interactions with the steroid receptors by PCP. Moreover, the observation of up-regulated brain gnrh, cyp $19 b$ and hepatic cyp $11 a$ could be viewed as an indication of a feed-forward response within the HPG axis in male rare minnow upon 14-d PCP exposure. Similarly, the up-regulation of $c r f$, pomc in the brain and kidney also indicated a feed-forward response within the HPI axis. The trigger of HPI axis was considered as indications for response to stressors such as environmental pollutants (Vijayan et al., 2003; Yang et al., 2011). However, gr mRNA levels were not changed in the kidney but significantly up-regulated in the liver. The in vitro results from the Pubchem database $(\mathrm{NIH}, 2016)$ indicated that PCP could interact with ER $\alpha$ but showed limit disrupting potency of with GR. Previously studies have proved that glucocorticoids play opposed roles with estrogens in several physiological processes and GR could inhibit transcriptional activation of ER (Uht et al., 1997). Therefore it seems reasonable that the up-regulated hepatic gr mRNA levels acted as an auto-regulation of the disturbed steroid hormones system.

However, after 28-d exposure to PCP, the feed-forward response of the HPG axis in male rare minnow seemed eased back. The transcription of hepatic er $\alpha, v t g, g r$ and gonadal $v t g$ still increased but with smaller fold-changes than those at 14th day; the transcription of brain gnrh hepatic ar and gonadal $\operatorname{er} \alpha$, er $\beta$ did not

Table 2

Plasma steroid hormones in rare minnow after exposure to PCP.

\begin{tabular}{|c|c|c|c|c|c|}
\hline \multicolumn{2}{|c|}{ Concentration $\left(\mu \mathrm{g} \cdot \mathrm{L}^{-1}\right)$} & \multirow{2}{*}{$\frac{\mathrm{E} 2(\mathrm{pg} / \mathrm{mL})}{227 \pm 22^{\mathrm{a}}}$} & \multirow{2}{*}{$\frac{\mathrm{T}(\mathrm{pg} / \mathrm{mL})}{207 \pm 24^{\mathrm{a}}}$} & \multirow{2}{*}{$\frac{C(\mathrm{ng} / \mathrm{mL})}{1147 \pm 137^{\mathrm{a}}}$} & \multirow{2}{*}{$\frac{\mathrm{E} 2 / \mathrm{T}}{1.09 \pm 0.49^{\mathrm{a}}}$} \\
\hline Female & Control & & & & \\
\hline & 0.5 & $341 \pm 40^{\mathrm{b}}$ & $963 \pm 115^{c}$ & $836 \pm 103^{b}$ & $0.35 \pm 0.14^{\mathrm{bc}}$ \\
\hline & 5 & $345 \pm 41^{\mathrm{b}}$ & $1362 \pm 163^{c}$ & $1073 \pm 128^{a}$ & $0.25 \pm 0.07^{c}$ \\
\hline & 50 & $249 \pm 30^{a}$ & $485 \pm 58^{\mathrm{b}}$ & $1174 \pm 140^{\mathrm{a}}$ & $0.51 \pm 0.14^{\mathrm{b}}$ \\
\hline \multirow[t]{4}{*}{ Male } & Control & $91.3 \pm 13^{\mathrm{a}}$ & $268 \pm 40^{\mathrm{a}}$ & $539 \pm 81^{\mathrm{a}}$ & $0.34 \pm 0.09^{\mathrm{a}}$ \\
\hline & 0.5 & $206 \pm 30^{b}$ & $797 \pm 12^{\mathrm{b}}$ & $778 \pm 116^{\mathrm{ab}}$ & $0.268 \pm 0.10^{\mathrm{b}}$ \\
\hline & 5 & $146 \pm 22^{\mathrm{a}}$ & $545 \pm 81^{\mathrm{b}}$ & $613 \pm 92^{\mathrm{ab}}$ & $0.27 \pm 0.08^{\mathrm{b}}$ \\
\hline & 50 & $89.1 \pm 15^{\mathrm{a}}$ & $270 \pm 44^{a}$ & $992 \pm 148^{b}$ & $0.33 \pm 0.11^{\mathrm{ab}}$ \\
\hline
\end{tabular}

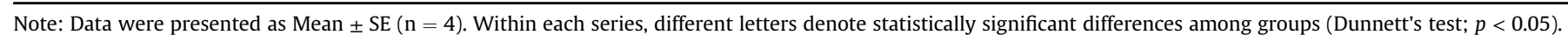




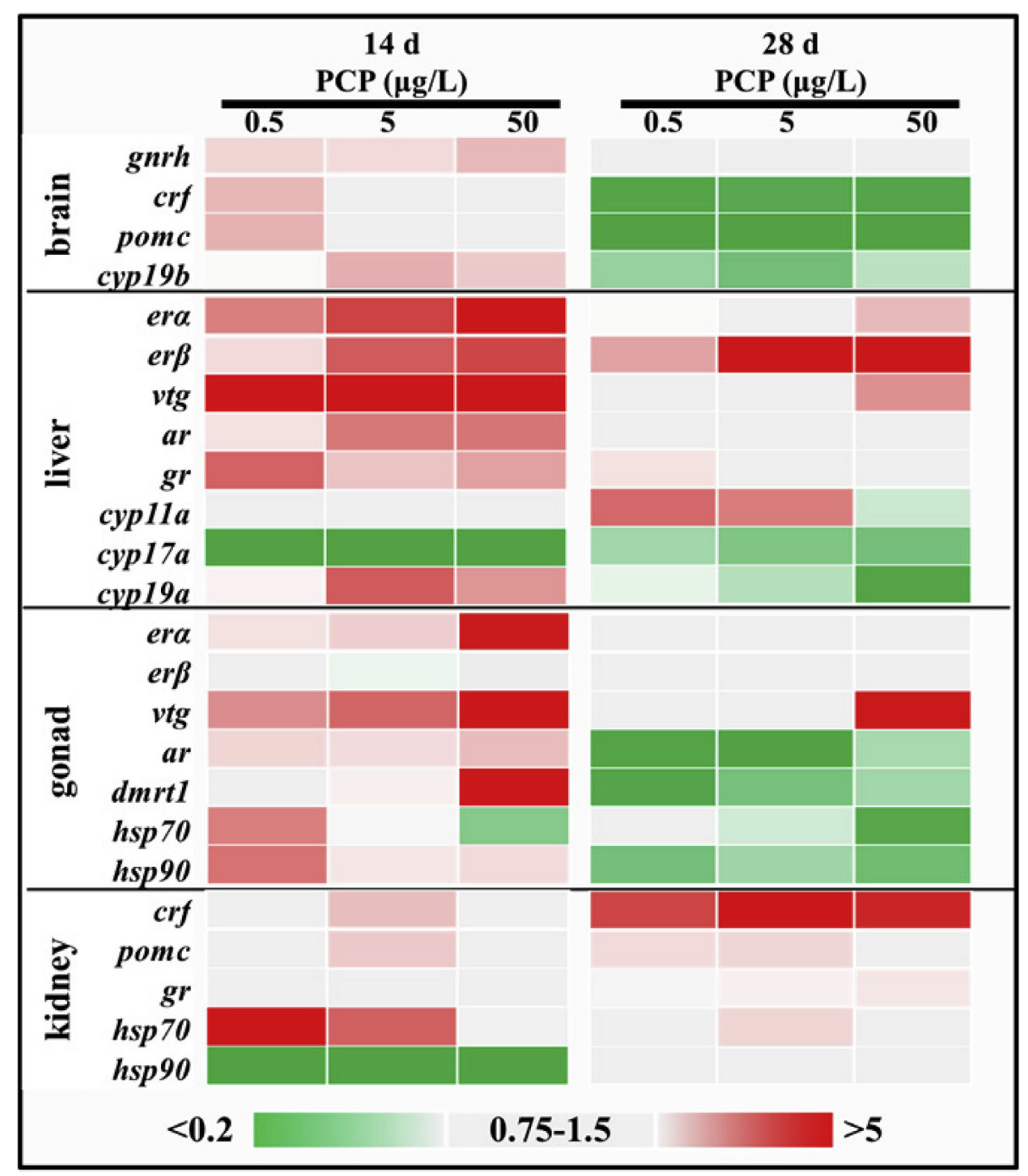

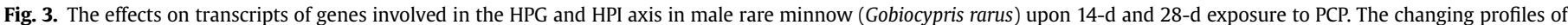
genes were represented by heat map.

change. These observations indicated a possibility of acclimatization to PCP evoked endocrine disruptions. Notably, the gene cyp11a showed increases at lower concentrations but decrease at highest concentration. Different time-course profiles of estrogen responsive genes and proteins have been reported in fish when exposed to exogenous (Andreassen et al., 2005; Park et al., 2009; Zha et al., 2006). The enzyme encoded by cyp11a play critical role in synthesis of steroid hormones from cholesterol. Thus the up-regulated cyp11a may be related to the increases of plasma sex steroid hormones, of which the changing profiles showed inverted U shaped dose-dependent relationships. Similar changing profiles have also been reported previously for serum $\mathrm{T}$ levels in crucian carp after exposure to PCP (Zhang et al., 2008a) and for plasma E2 levels in zebrafish (Danio rerio) after exposure to fluorotelomer alcohols (Liu et al., 2009). One possible explanation for this could be different responsive profiles upon various doses exposure. Alternatively, the monotonic dose-response relationships could be explained by different interference mechanisms, i.e., hormesis at lower concentration and toxic effects at higher concentration (Welshons et al., 2003; Zhang et al., 2008a).

In addition, brain cyp19b, hepatic cyp19a and gonadal ar, dmrt1, hsp90 were decreased, and this may indicated a negative feedback response within HPG axis following the disturbed homeostasis of steroid hormones after 28-d exposure to PCP. The enzymes encoded by cyp19 catalyze the conversion of T to E2 (Yaron and LevaviSivan, 2011), and the decreased brain cyp19b and hepatic cyp19a in the present study would be related to the decreased ratio of E2/T. The down-regulated gonadal ar and dmrt1 mRNA may be related to the observation of increased ratio of SG and decreased ratio of SZ in testis after 28-d exposure. We also found that the transcriptional profiles of ers and ar were different in liver and gonad in male fish. Tissue-dependent response of steroid receptors to exogenous chemicals have been reported in rats (Williams et al., 1989). Li et al. (2007) found that whether the exogenous ligand behaves primarily as an agonist or antagonist was determined by the ratio of coactivators to corepressors of the receptors. The HSPs, which mainly contribute to the folding, maintenance of structural integrity, and proper regulation of steroid receptors, has been used as sensitive biomarkers to environmental stressors (Yang et al., 2010). Recent study by Liu et al. (2015) demonstrated a dose-dependent and time-dependent response of HSP90 to PCP exposure in rare minnow juveniles. The down-regulated hsp70 and hsp90 transcription in the present study suggested a regulatory role of these chaperones in steroid receptor mediated endocrine disruptions. 


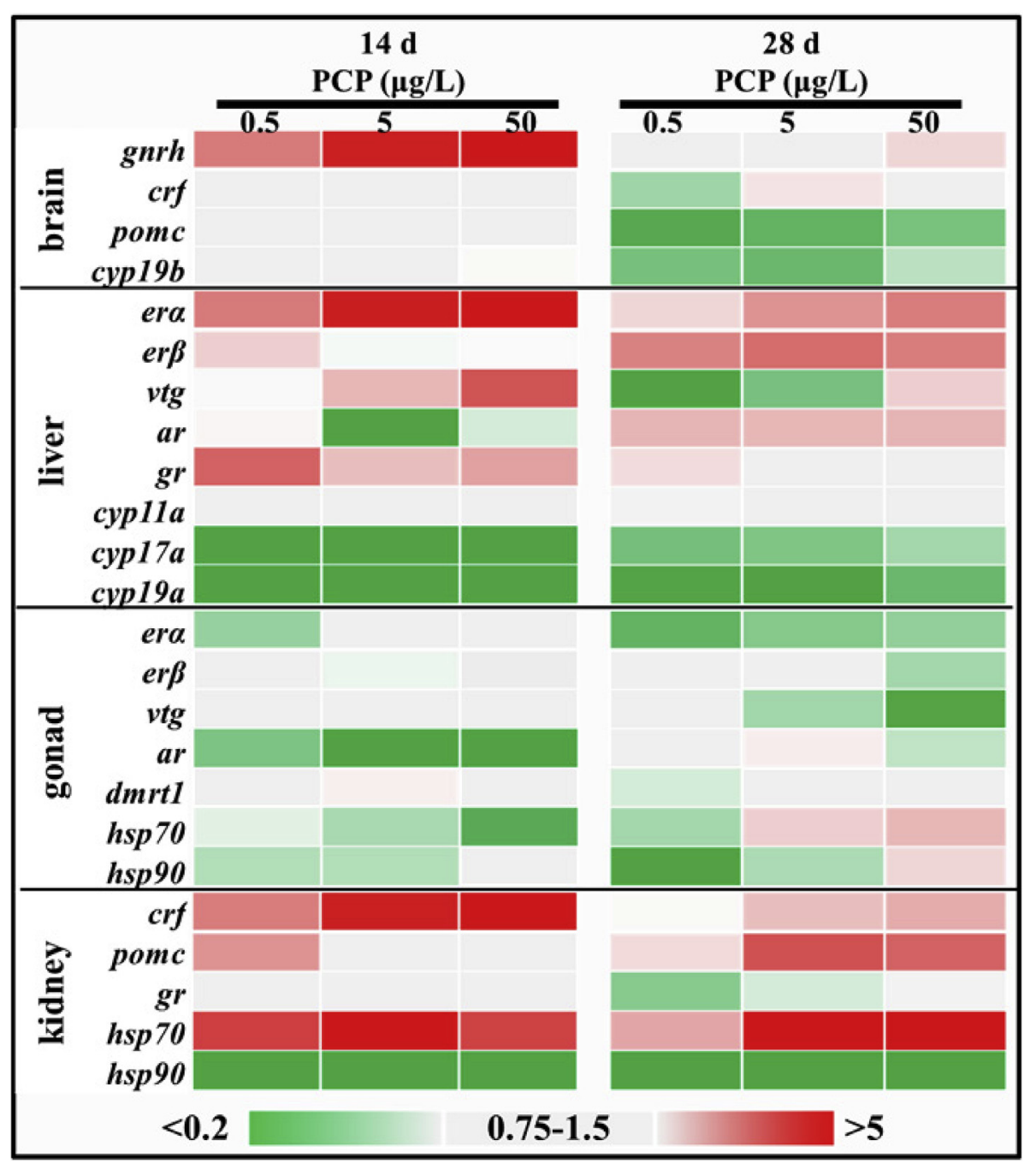

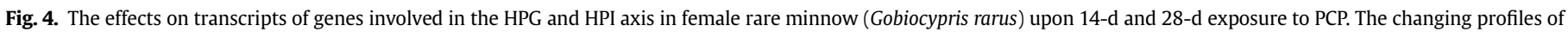
genes were represented by heat map.

Similarly, the down-regulated brain crf, pomc also indicated a negative feedback response within the HPI axis, whereas the upregulated renal crf, pomc, gr suggested localized feed-forward response was still exist in the interrenal tissue. These results also suggested different time-course profiles between HPG and HPI axis in response to PCP exposure. The decreased RSI and histopathological observations including degradated glomerulus and necrosis of the tubular epithelia indicated lesions of the interrenal system. Taken together, our results suggested that PCP could interfere with steroid receptors and resulted in adverse effects on both reproductive and interrenal system in male rare minnow, perhaps under the assistance of auxiliary factors such as coactivators and molecular chaperones.

In the case of female fish, 14-d exposure to PCP evoked feedforward response in the brain as indicated by increases of gnrh mRNA levels. The up-regulated hepatic er $\alpha$, vtg and gr mRNA levels provided evidence for agonistic effects on ER $\alpha$ and GR by PCP in liver tissue. The down-regulated ar mRNA levels in the ovary suggested a possibility of AR antagonism in this tissue. Alternatively, down-regulated gonadal mRNA levels of ar, maybe also of er $\alpha$ and their molecular chaperones $h s p 70 / 90$, could be viewed as localized negative feedbacks following disturbance of sex steroids homeostasis. After 28-d exposure to PCP, the increases of mRNA levels of brain ghrh, hepatic er $\alpha$ and gr eased back to some extent, whereas the mRNA levels of brain cyp $19 b$ and gonadal $\operatorname{er} \alpha, \operatorname{er} \beta, v \operatorname{tg}$, ar and dmrt1 decreased significantly. Meantime, hepatic vtg and gonadal hsp70/90 decreased at lower PCP concentrations and increased at higher PCP concentrations. Taken together, these results may suggest a transition from a feed-forward response to a negative feedbacks of the HPG axis.

Although no promotions of cyp11a transcription were observed at neither 14 nor $28 \mathrm{~d}$, plasma E2 and T were still increased in female rare minnow. One possible explanation was the changeover of cyp11a transcriptional profile occurred even earlier. The decreased ratio of E2/T and down-regulated mRNA levels of hepatic vtg (lower concentrations) and gonadal er $\alpha$, er $\beta, v t g$ may be related to the histopathological observations and including increased percentage of PO upon exposure to $0.5 \mu \mathrm{g} \mathrm{L}^{-1} \mathrm{PCP}$ and increased occurrences of atresia upon exposure to 5 and $50 \mu \mathrm{g} \mathrm{L}^{-1} \mathrm{PCP}$. Correspondingly, the GSI of female fish were also decreased in $0.5 \mu \mathrm{g} \mathrm{L}^{-1}$ PCP treatments. Similar effects have been reported in previous studies which reported decreased GSI and degeneration of ovaries in fathead minnow (Pimephales promelas), zebrafish, medaka (Oryzias latipes), catfish (Heteropneustes fossilis) and rare minnow upon exposure to EE2 and other estrogenic chemicals (Pawlowski et al., 2004; Seki et al., 2002; Van den Belt et al., 2001; Zha et al., 2007; Ghosh and 
Thomas, 1995; Srivastava and Srivastava, 1994). These results suggested that PCP could interfere with steroid receptors and disturb the HPG axis, thus resulted in adverse effects such as hormone disturbances and gonadal degeneration in female fish.

In the present study, the HPI axis of rare minnow may also undergo a transition in responsive status since brain $\mathrm{crf}$ and pomc mRNA levels showed no changes after 14-d exposure, but significantly down-regulated after 28-d exposure. In the kidney, a localized feed-forward response may be sustained as up-regulation of crf, pomc were observed at both 14th and 28th day. Anyway, these results indicated stress response of the HPI axis evoked by PCP exposure. Similar with the results in male fish, gr mRNA levels did not change in the kidney but significantly up-regulated in the liver at 14th day, confirming previous speculation that an autoregulation may exist among steroid receptors pathways in response to PCP exposure. Whereas at 28th day, renal gr mRNA showed significant decrease at lower PCP concentrations. Consistently, plasma $C$ level was observed decreased at only $0.5 \mu \mathrm{g} \mathrm{L}^{-1}$ PCP. The decreased plasma $C$ and renal gr mRNA may be related to the decreased RSI of female fish in the present study. These results provide additional evidence for the stress responsive status of HPI axis in rare minnow evoked by PCP exposure. Previous studies have demonstrated chronic estrogen-induced alterations in glucocorticoid receptor-mediated functions (Burgess and Handa, 1992) and also a role of ER $\alpha$ in the process (Weiser and Handa, 2009). Hence it seems reasonable that the interaction with ERs other than GR may act as the main MIE responsible for the observed disturbance of steroid hormones system by PCP.

Overall, our results demonstrated significant disturbance on both HPG and HPI axis in rare minnow upon PCP exposure, and the different transcriptional changing profiles at 14th and 28th d suggested the importance of proper exposure period and assessment endpoints and could be indicative for toxicological research. Besides, the final outcomes and major molecular pathways driving the observed effects seem different between male and female fish. It is also worthwhile to note that pronounced adverse effects were observed at the lowest concentration of PCP of the study (i.e. $\left.0.5 \mu \mathrm{g} \mathrm{L}^{-1}\right)$, which is even lower than the aquatic exposure level in China (up to $594.0 \mathrm{ng} \mathrm{L}^{-1}$ ) (Jin et al., 2012b), and this may suggest that the current standards for PCP in drinking water of China (9 $\mu \mathrm{g} \mathrm{L}^{-1}$, Xia et al., 2004) would not provide enough protection to native aquatic species. Although there were limited evidences for the interruption of PCP on the steroidogenesis of mammalian or human beings, the evidences from present work indicated ecological risk for aquatic animals living in Chinese waters (Jin et al., 2012b), and highlighted the importance of application of data on different toxicological endpoints from sub-chronic or chronic toxicity in risk assessment. Further research is required to elucidate the multi-generation effects of PCP at environmental relevant concentrations.

\section{Conclusions}

In conclusions, our results suggested that PCP could interfere with steroid receptors, disturb the steroid homeostasis thus result in adverse effects on both reproductive and interrenal system in rare minnow at environmentally relevant concentrations.

\section{Acknowledgements}

This work was supported by the National Natural Science Foundation of China (21307153, 21407166), and Beijing Natural Science Foundation (8152017).

\section{Appendix A. Supplementary data}

Supplementary data related to this article can be found at http:// dx.doi.org/10.1016/j.chemosphere.2016.09.099.

\section{References}

Andreassen, T.K., Skjoedt, K., Korsgaard, B., 2005. Upregulation of estrogen recepto alpha and vitellogenin in eelpout (zoarces viviparus) by waterborne exposure to 4-tert-octylphenol and 17beta-estradiol. Comp. Biochem. Physiol. C Toxicol. Pharmacol. 140, 340-346.

Bjornstrom, L., Sjoberg, M., 2005. Mechanisms of estrogen receptor signaling: convergence of genomic and nongenomic actions on target genes. Mol. Endocrinol. 19, 833-842.

Burgess, L.H., Handa, R.J., 1992. Chronic estrogen-induced alterations in adrenocorticotropin and corticosterone secretion, and glucocorticoid receptor- mediated functions in female rats. Endocrinology 131, 1261-1269.

Chen, H.M., Lee, Y.H., Wang, Y.J., 2015. Ros-triggered signaling pathways involved in the cytotoxicity and tumor promotion effects of pentachlorophenol and tetrachlorohydroquinone. Chem. Res. Toxicol. 28 (3), 339-350.

Davies, P.E., Cook, L.S.J., Goenarso, D., 1994. Sublethal responses to pesticides of several species of Australian fresh-water fish and crustaceans and rainbowtrout. Environ. Toxicol. Chem. 13, 1341-1354.

Fang, Y., Gao, X., Zha, J., Ning, B., Li, X., Gao, Z., Chao, F., 2010. Identification of differential hepatic proteins in rare minnow (Gobiocypris rarus) exposed to pentachlorophenol (PCP) by proteomic analysis. Toxicol. Lett. 199, 69-79.

Gao, J., Liu, L., Liu, X., Zhou, H., Huang, S., Wang, Z., 2008. Levels and spatial distribution of chlorophenols-2,4-dichlorophenol, 2,4,6-trichlorophenol, and pentachlorophenol in surface water of China. Chemosphere 71, 1181-1187.

Ge, J., Pan, J., Fei, Z., Wu, G., Giesy, J.P., 2007. Concentrations of pentachlorophenol PCP) in fish and shrimp in Jiangsu Province, China. Chemosphere 69, 164-169.

Ghosh, S., Thomas, P., 1995. Antagonistic effects of xenobiotics on steroid induced final maturation of Atlantic croaker oocytes in vitro. Mar. Environ. Res. 39 159-163.

Han, F., Chen, L., Ji, W., Li, X., Zhou, C., Hu, Y., 2009. A comparison of VOCs, SVOCs contents of Yangtze River water and main surface water in Jiangsu, Zhejiang and Shandong. J. Preven. Med. Inf. 25, 161-167 (in Chinese).

Jin, X., Zha, J., Xu, Y., Giesy, J.P., Wang, Z., 2012a. Toxicity of pentachlorophenol to native aquatic species in the yangtze river. Environ. Sci. Pollut. R. 19 (3), $609-618$

Jin, X., Zha, J., Xu, Y., Wang, Z., Giesy, J., Richardson, K., 2012b. A tiered ecological risk assessment of three chlorophenols in Chinese surface waters. Environ. Sci. Pollut. Res. 19, 1544-1554.

Jung, J., Ishida, K., Nishihara, T., 2004. Anti-estrogenic activity of fifty chemicals evaluated by in vitro assays. Life Sci. 74, 3065-3074.

Kurosawa, T., Hiroi, H., Tsutsumi, O., Ishikawa, T., Osuga, Y., Fujiwara, T., Inoue, S. Muramatsu, M., Momoeda, M., Taketani, Y., 2002. The activity of bisphenol A depends on both the estrogen receptor subtype and the cell type. Endocr. J. 49, 465-471.

Li, L., Andersen, M.E., Heber, S., Zhang, Q., 2007. Non-monotonic dose-response relationship in steroid hormone receptor-mediated gene expression. J. Mol. Endocrinol. 38, 569-585.

Li, J., Ma, M., Wang, Z., 2008a. A two-hybrid yeast assay to quantify the effects of xenobiotics on thyroid hormone-mediated gene expression. Environ. Toxicol Chem. 27, 159-167.

Li, J., Ma, M., Wang, Z., 2008b. A two-hybrid yeast assay to quantify the effects of xenobiotics on retinoid $\mathrm{X}$ receptor-mediated gene expression. Toxicol. Lett. 176, 198-206.

Li, F., Xie, Q., Li, X.H., Li, N., Chi, P., Chen, J.W., Wang, Z.J., Hao, C., 2010a. Hormone activity of hydroxylated polybrominated diphenyl ethers on human thyroid receptor-beta: in vitro and in silico investigations. Environ. Health Perspect. 118 602-606.

Li, J., Ma, M., Wang, Z., 2010b. In vitro profiling of endocrine disrupting effects of phenols. Toxicol. In Vitro 24, 201-207.

Li, X., Ye, L., Wang, X., Wang, X., Liu, H., Zhu, Y., Yu, H., 2012. Combined 3D-QSAR, molecular docking and molecular dynamics study on thyroid hormone activity of hydroxylated polybrominated diphenyl ethers to thyroid receptors $\beta$. Toxicol. App. Pharmacol. 265 (3), 300-307.

Liu, C.S., Yu, L.Q., Deng, J., Lam, P.K., Wu, R.S.S., Zhou, B.S., 2009. Waterborne exposure to fluorotelomer alcohol 6: $2 \mathrm{FTOH}$ alters plasma sex hormone and gene transcription in the hypothalamic-pituitary-gonadal (HPG) axis of zebrafish. Aquat. Toxicol. 93, 131-137.

Liu, Q., Huang, S., Deng, C., Xiong, L., Gao, X., Chen, Y., Niu, C., 2015. Molecular characterization of heat-shock protein 90 gene and its expression in gobiocypris rarus juveniles exposed to pentachlorophenol. Fish. Physiol. Biochem. 41 (5), 1279-1291.

Marchand, O., Govoroun, M., D'Cotta, H., McMeel, O., Lareyne, J., Bernot, A., Laudet, V., Guiguen, Y., 2000. DMRT1 expression during gonadal differentiation and spermatogenesis in the rainbow trout, Oncorhynchus mykiss. Biochim. Biophys. Acta 1493, 180-187.

Matson, C.K., Murphy, M.W., Griswold, M.D., Yoshida, S., Bardwell, V.J., Zarkower, D. 2010. The mammalian doublesex homolog dmrt1 is a transcriptional gatekeeper that controls the mitosisversus meiosis decision in male germ cells. Dev. 
Cell 19, 612-624.

Nagahama, Y., Yoshikuni, M., Yamashita, M., Tokumoto, T. Katsu, Y., 1994. Regulation of oocyte growth and maturation in fish. In: Nilsen-Hamilton, M. (Ed.), Current Topics in Developmental Biology, vol. 30. Academic Press Inc., New York pp. 103-146.

U.S. National Institutes of Health (NIH), 2016. Database of Pubchem Bioassay (accessed 16.03.03). https://pubchem.ncbi.nlm.nih.gov/assay/bioactivity.html? cid $=992$.

Ohtani, H., Miura, I., Ichikawa, Y., 2003. Role of aromatase and androgen receptor expression in gonadal sex differentiation of zw/zz-type frogs, rana rugosa. Comp. Biochem. Phys. C 134, 215-225.

Orton, F., Lutz, I., Kloas, W., Routledge, E.J., 2009. Endocrine disrupting effects of herbicides and pentachlorophenol: in vitro and in vivo evidence. Environ. Sci. Technol. 43, 2144-2150.

Park, C.B., Aoki, J.Y., Lee, J.S., Nagae, M., Lee, Y.D., Sakakura, Y., Hagiwarab, A. Soyanoa, K., 2009. The effects of $17 \beta$-estradiol on various reproductive parameters in the hermaphrodite fish kryptolebias marmoratus. Aquat. Toxicol. 96, 273-279.

Pawlowski, S., van Aerle, R., Tyler, C.R., Braunbeck, T., 2004. Effects of $17 \alpha$ - ethinylestradiol in a fathead minnow (Pimephales promelas) gonadal recrudescence assay. Ecotoxicol. Environ. Saf. 57, 330-345.

Pietsch, C., Hollender, J., Dorusch, F., Burkhardt-Holm, P., 2014. Cytotoxic effects of pentachlorophenol (PCP) and its metabolite tetrachlorohydroquinone (TCHO) on liver cells are modulated by antioxidants. Cell Biol. Toxicol. 30, 233-252.

Seki, M., Yokota, H., Matsubara, H., Tsuruda, Y., Maeda, M., Tadokoro, H. Kobayashi, K., 2002. Effect of ethinylestradiol on the reproduction and induction of vitellogenin and testis-ova in medaka (Oryzias latipes). Environ. Toxicol. Chem. 21, 1692-1698.

Shibata, K., Takase, M., Nakamura, M., 2002. The Dmrt1 expression in sex-reversed gonads of amphibians. Gen. Comp. Endocrinology 127, 232-241.

Srivastava, A.K., Srivastava, A.K., 1994. Effect of chlordecone on gonads of freshwater catfish, Heteropneustes fossilis. Bull. Environ. Contam. Toxicol. 53, 186-191.

Suzuki, T., Ide, K., Ishida, M., 2001. Response of MCF-7 human breast cancer cells to some binary mixtures of oestrogenic compounds in vitro. J. Pharm. Pharmacol. $53,1549-1554$

Uht, R.M., Anderson, C.M., Webb, P., Kushner, P.J., 1997. Transcriptional activities of estrogen and glucocorticoid receptors are functionally integrated at the ap-1 response element. Endocrinology 138, 2900-2908.

Van den Belt, K., Verheyen, R., Witters, H., 2001. Reproductive effects of ethynylestradiol and 4-t-octylphenol on the zebrafish (Danio rerio). Arch. Environ. Contam. Toxicol. 41, 458-467.

Vijayan, M.M., Raptis, S., Sathiyaa, R., 2003. Cortisol treatment affects glucocorticoid receptor and glucocorticoid-responsive genes in the liver of rainbow trout. Gen. Comp. Endocr. 132, 256-263.

Wang, H., Tan, J.T.T., Emelyanov, A., Korzh, V., Gong, Z., 2005. Hepatic and extrahepatic expression of vitellogenin genes in the zebrafish, Danio rerio. Gene 356, 91-100.

Weiser, M.J., Handa, R.J., 2009. Estrogen impairs glucocorticoid dependent negative feedback on the hypothalamic-pituitary-adrenal axis via estrogen receptor alpha within the hypothalamus. Neuroscience 159, 883-895.

Welshons, W.V., Thayer, K.A., Judy, B.M., Taylor, J.A., Curran, E.M., vom Saal, E.S., 2003. Large effects from small exposuresl. Mechanisms for endorcrinedisrupting chemicals with estrogenic activity. Environ. Health. Perspect. 111, 944-1006.
Williams, J., Eckols, K., Uphouse, L., 1989. Estradiol and chlordecone interactions with the estradiol receptor. Toxicol. Appl. Pharmacol. 98, 413-421.

Wolf, J.C., Dietrich, D.R., Friederich, U., Caunter, J., Brown, A.R., 2004. Qualitative and quantitative histomorphologic assessment of fathead minnow (Pimephales promelas) gonads as an endpoint for evaluating endocrine-active compounds: a pilot methodology study. Toxicol. Pathol. 32, 600-612.

Xia, Q., Chen, Y., Liu, X., 2004. Water Quality Criteria and Standards. Standard Press in China. Beijing (in Chinese).

Yang, L., Zha, J., Zhang, X., Li, W., Li, Z., Wang, Z., 2010. Alterations in mRNA expression of steroid receptors and heat shock proteins in the liver of rare minnow (grobiocypris rarus) exposed to atrazine and p,p'-DDE. Aquat. Toxicol. $98(4), 381-387$.

Yang, L., Zha, J., Li, W., Li, Z., Wang, Z., 2011. Vinclozolin affects the interrenal system of rare minnow (Gobiocypris rarus). Aquat. Toxicol. 104, 153-159.

Yaron, Z., Gur, G., Relamed, P., Rosenfeld, H., Elizur, H., Levavi-Sivan, B., 2003. Regulation of fish gonadotropins. In: Kwang. W.J. (Ed.), International Review of Cytology-A Survey of Cell Biology, vol. 225. Academic Press Inc., San Diego, pp. $131-185$

Yaron, Z., Levavi-Sivan, B., 2011. Endocrine regulation of fish reproduction. In: Farrell, A.P. (Ed.), Encyclopedia of Fish Physiology: from Genome to Environment, vol. 2. Academic Press Inc., Oxford, pp. 1500-1509.

Yin, D., Gu, Y., Li, Y., Wang, X., Zhao, Q., 2006. Pentachlorophenol treatment in vivo elevates point mutation rate in zebrafish p53 gene. Mutat. Rese-Gen. Tox. Environ. Mutag 609, 92-101.

Zha, J., Wang, Z., Schlenk, D., 2006. Effects of pentachlorophenol on the reproduction of Japanese medaka (Oryzias latipes). Chem.-Biol. Interact. 161, 26-36.

Zha, J., Wang, Z., Wang, N., Ingersoll, C., 2007. Histological alternation and vitellogenin induction in adult rare minnow (Gobiocypris rarus) after exposure to ethynylestradiol and nonylphenol. Chemosphere 66, 488-495.

Zha, J., Sun, L., Zhou, Y., Spear, P.A., Ma, M., Wang, Z., 2008. Assessment of 17 alphaethinylestradiol effects and underlying mechanisms in a continuous, multigeneration exposure of the Chinese rare minnow (Gobiocypris rarus). Toxicol. Appl. Pharm. 226, 298-308.

Zhang. M. Yin, D. Kong, F., 2008a. The changes of serum testosterone level and hepatic microsome enzyme activity of crucian carp (Carassius carassius) exposed to a sublethal dosage of pentachlorophenol. Ecotox. Environ. Safe 71, $384-389$

Zhang, X., Zha, J., Li, W., Yang, L., Wang, Z., 2008b. Effects of 2,4-dichlorophenol on the expression of vitellogenin and estrogen receptor genes and physiology impairments in Chinese rare minnow (Gobiocypris rarus). Environ. Toxicol. 23, 694-701.

Zheng, M., Zhang, B., Bao, Z., Yang, H., Xu, X., 2000. Analysis of pentachlorophenol from water, sediments, and fish bile of Dongting Lake in China. B. Environ. Contam.Toxicol 64, 16-19.

Zheng, W., Wang, X., Yu, H., Tao, X., Zhou, Y., Qu, W., 2011. Global trends and diversity in pentachlorophenol levels in the environment and in humans: a metaanalysis. Environ. Sci. Technol. 45, 4668-4675.

Zheng, W., Yu, H., Wang, X., Qu, W., 2012. Systematic review of pentachlorophenol occurrence in the environment and in humans in China: not a negligible health risk due to the re-emergence of schistosomiasis. Environ. Int. 42, 105-116.

Zhong, W. Wang, D., Xu, X., Wang, B., Luo, Q. Senthil, K., Wang, Z., 2011. A gas chromatography/mass spectrometry method for the simultaneous analysis of 50 phenols in wastewater using deconvolution technology. Chin. Sci. Bull. 56, 275-284. 